\title{
A IGREJA DO EVANGELHO QUADRANGULAR NAS ELEIÇÕES DE 2006: A DISPUTA PELA VAGA DE DEPUTADO FEDERAL
}

\author{
Rosilene Schoenfelder \\ Joice Lisa Zenatti Paz*
}

Resumo: É cada vez maior a participação de denominaçōes religiosas no campo político, especialmente das candidaturas evangélicas. No que tange a Igreja Evangelho Quadrangular, objeto desta pesquisa, foi observado que as movimentaçôes com vista a sua participação nas eleições de 2006 se iniciaram no ano de 2005 com a realização de pleito interno. No intuito de compreender como se deu este processo que levou a referida igreja à conquista de vagas no legislativo estadual e federal este artigo busca historicizar a sua participação na política gaúcha. Em um segundo momento, através de entrevistas foi possível compreender a dinâmica deste processo e quais as implicaçôes do pleito interno na forma como se produziram e se organizaram as candidaturas. Neste sentido, buscou-se subsídios para entender como as candidaturas são percebidas, seja do ponto de vista institucional, seja do ponto de vista não-institucional.

Palavras-chave: Eleiçōes 2006, Igreja Evangelho Quadrangular, Política, Rio Grande do Sul, Religião

\section{INTRODUÇÃO}

É cada vez maior a participação de denominaçōes religiosas no campo político. Dentre os muitos estudiosos que se ocupam do tema, é interessante destacar os dados trazidos por Oro (2004) e Pedde (2005), entre outros, no que se refere à participação das diversas igrejas evangélicas no cenário político gaúcho. Dentre as principais constataçôes feitas por estes autores, apontamos o crescimento das candidaturas evangélicas, em especial, destacando a forma como tem se inserido a Igreja Universal do Reino de Deus, a Igreja do Evangelho Quadrangular e a Assembléia de Deus ${ }^{1}$.

\footnotetext{
* Estudante de graduação do Curso de Ciências Sociais da UFRGS e bolsista BIC/UFRGS do Núcleo de Estudos da Religião (NER).

** Estudante de graduação do Curso de Ciências Sociais da UFRGS.

${ }^{1}$ A partir deste momento iremos nos referir à Igreja Universal do Reino de Deus como IURD, à Igreja Assembléia de Deus como AD e à Igreja do Evangelho Quadrangular como IEQ.
} 
No que tange a IEQ, objeto de nossa pesquisa, observamos que as movimentaçôes com vista a sua participação nas eleições de 2006 se iniciaram no ano de 2005 com a realização do pleito interno ${ }^{2}$, onde foram apresentados e analisados os nomes dos candidatos que possuíam interesse de se inserir no campo político, para após serem submetidos a um processo de votação in terno. Este processo - o pleito - definiu quais seriam os candidatos oficiais que disputariam alguma vaga para os cargos de Deputado Estadual e Deputado Federal nas eleições de 2006 apoiados pela Igreja.

No intuito de compreendermos como se deu este processo que levou a IEQ à conquista de vagas no legislativo municipal e estadual buscaremos nas páginas a seguir historicizar a participação da IEQ na política gaúcha. Para, num segundo momento, através das entrevistas realizadas com os candidatos Reinaldo Santos e Silva e Nilo Sérgio Santos dos Santos, ambos pastores da IEQ, compreendermos a dinâmica desse processo e quais as implicaçóes do pleito interno na forma como se produziram e se organizaram as duas candidaturas ora apresentadas, devido ao fato de, o primeiro ser um candidato oficial e o segundo não oficial. Nesse sentido, pretendemos buscar subsídios para entender como ambas as candidaturas são percebidas, seja do ponto de vista institucional, seja do ponto de vista não-institucional. Para isto, nós usaremos das entrevistas realizadas com os candidatos e, também, suas manifestações no horário eleitoral televisivo.

\section{HISTORICIZANDO A INSERÇÃO DA IEQ NA POLÍTICA}

Desde sua inserção na política, a IEQ sempre se caracterizou por uma forma de organização interna incomum às outras denominaçōes evangélicas. Destacamos, em especial, as aspectos referentes à sua organização burocrática, uma vez que estas outras denominaçôes ${ }^{3}$ reconhecem seus candidatos por indicação da própria instituição. Tal indicação, se dá através das decisões de uma cúpula dirigente local que indica e declara quem serão os candidatos que receberão o apoio oficial da Igreja. Não existindo, como exposto por Oro (2006), um desaconselhamento quanto à participaçáo de outros membros.

Nesse sentido, a IEQ privilegia um procedimento democrático de escolha dos candidatos oficiais semelhante às prévias que ocorrem dentro dos partidos políticos. Um ano antes das eleições, é realizado um pleito interno, em que os pastores de todo estado reúnem-se para votar e decidir quem serão os candidatos apoiados, dentre os que se apresentam, segundo os princípios estatutários que regem esta organização. De modo que, os nãoeleitos no pleito não serão reconhecidos pela Instituição como candidatos oficiais.

Desta forma, o presente trabalho tem por finalidade investigar a inserção da IEQ na política partidária e seu papel como representante de um segmento crescente em nossa sociedade, pois de acordo com os dados do IBGE, 1,07\% dos gaúchos se declaram mem-

\footnotetext{
${ }^{2}$ Momento de discussão e votação para escolha dos candidatos às eleições, tanto em âmbito municipal, estadual e federal, apoiados pela Igreja. Pode ser encontrado no artigo como prévia.

${ }^{3}$ Igreja Universal do Reino de Deus e Assembléia de Deus.
} 
bros da IEQ, o que corresponde a 108.748 pessoas $^{4}$. Ainda nesta direção, Pedde (2005) observa que em 1986, após a realização da Assembléia Nacional Constituinte, a política institucional passou a introduzir-se nas igrejas evangélicas, fato que, incrementou o número de congregações/denominaçóes evangélicas envolvidas com a política partidária. No caso da IEQ, tal envolvimento com o campo político se deu a partir da possibilidade de ampliação e desenvolvimento da estrutura desta denominação, pela necessidade de ética na política, esta, vista como um espaço contaminado pela corrupção.

Assim, a partir do ano de 2000, um novo procedimento é adotado pela IEQ em relação a sua inserção na política, pois, até então, esta não possuía uma estrutura organizacional que indicasse candidatos oficiais. Em conseqüência disso e a fim de aumentar a eficácia de seus resultados, é adotado, a partir deste ano, um estilo "iu rdiano" de lançar "candidatos oficiais". Fato que resultou na conquis ta de mais oito vagas para vereador, em relação à eleição anterior.

Tal estilo se fez presente nos anos seguintes, em especial, no ano de 2002, na prévia realizada pela IEQ, quando foi indicado o já Deputado Estadual Manoel Maria, como candidato oficial, e para a Câmara Federal, o Pastor Reinaldo Santos e Silva, ambos do Partido Trabalhista Brasileiro (PTB), sendo que foram eleitos, o primeiro com 38.361 votos e o segundo com 43.716 votos (Oro, 2003). Em 2004, o Pastor Nilo Santos disputou para a Câmara de Vereadores de Porto Alegre, obtendo um total de 4.482 votos, elegendo-se como segundo suplente, pelo PTB.

Desta forma, podemos observar nos resultados apresentados acima, que a IEQ através desta nova forma de organização interna, passa a confirmar a crescente participação dos evangélicos no espectro político partidário. Passemos pois, a essa forma de organização particular - o pleito.

\section{O PLEITO}

A partir das entrevistas realizadas com os referidos candidatos, notou-se uma divergência quanto ao processo de escolha dos candidatos oficiais dentro da IEQ. Nas entrevistas, ambos foram questionados sobre suas percepçôes a respeito deste momento de discussão. Com base na declaração realizada pelo Pastor Reinaldo Santos, ao se referir à lógica do processo, entende-se que:

“(...) a Igreja indica um para federal e um para estadual. E as lideranças procuram trabalhar em cima desses dois, um pra federal e um pra estadual".

\footnotetext{
${ }^{4}$ Ver: http://www.ibge.gov.br

5 Entende-se por pessoas vinculadas à Igreja que possuem uma trajetória dentro da instituição e têm seu nome indicado e apoiado pela mesma.
} 
Nota-se que a estratégia utilizada é a de captar eleitores em todo estado na busca de eleger apenas um só candidato em ambos os cargos, já que o número de membros no estado é suficiente para eleger um deputado federal e um estadual.

Ao referir-se às eleiçóes deste ano, tanto o Pastor Reinaldo Santos quanto o candidato Nilo Santos, expóem suas análises sobre a forma como se deu o pleito no ano passado, apresentando o processo sob duas perspectivas diferentes:

Pastor Reinaldo Santos: "Na nossa Igreja estão concorrendo dois candidatos, digamos oficiais, que sou eu e outro colega de Cachoeira do Sul, o Pastor Uberani Barbosa, então ele é o candidato estadual (...) ele é o candidato a Deputado Estadual e nós dois somos aquilo que diríamos indicados pelos pastores da Igreja. Isso porque a gente faz uma convenção um ano antes, nós fizemos em setembro do ano passado, uma convenção para escolher os candidatos que a Igreja vai apoiar efetivamente, e nessa eleição eu participei sozinho concorrendo para federal e o Pastor Uberani Barbosa concorreu com o Nilo, que é candidato hoje para federal. Ele concorreu à indicação para estadual, perdeu para o Pastor Uberani Barbosa, aí se lançou a candidato federal. Mas aí, não sei por que, pois a intenção dele é se projetar pra ser vereador em Porto Alegre, então ele lançou-se à revelia da Igreja a candidato a Deputado Federal, quer dizer, ele é candidato legalmente, é um cidadão ligado a um partido, mas não é aquele candidato que a Igreja indicou.”

Nilo Santos: "A Quadrangular convoca para uma prévia todos os pastores e os obreiros, tempo integral, que têm direito a voto. Hoje dá em torno de mil e duzentos da Quadrangular. Mais ou menos mil e duzentos votos de todo Estado. E, então vão para prévia, os que querem concorrer, se inscrevem antes e é enviada então uma circular para todos os pastores os nomes que estão concorrendo. E é marcado o dia da prévia, então e os pastores se deslocam para aquela cidade e votam, candidato A ou B, para estadual, A ou B, para federal".

Com isto, é possível observar que o pleito é um processo muito bem construído e articulado, onde todos os pastores participam de forma democrática, oficializando ou não os nomes de quem contará com o apoio efetivo da Igreja. Como se vê no discurso do Pastor Rein aldo Santos, candidato oficial da IEQ, ex iste um "livre-arbítrio" na concorrência política, mesmo que à revelia da Igreja, pois cada membro é visto como um cidadão com direitos civis e apto a candidatar-se. Embora, muitas vezes, possa ocorrer que o membro da denominação que se candidata, sem ter sido escolhido neste processo, tenha desvantagens em relação ao candidato oficial, principalmente no que se refere à divulgaçáo de sua campanha.

Neste sentido, de acordo com Cleomar Ferraz, pastor suplente da IEQ, entrevistado no Conselho Estadual de Diretores da IEQ do Estado do Rio Grande do Sul, existe um estatuto interno que delimita o funcionamento do pleito, onde apenas um candidato pode ser indicado legalmente a concorrer, no caso, foi aprovado o Pastor Reinaldo. Já o candidato Nilo é visto como escolhido pela legenda do partido. O que acaba refletindo na forma diferenciada de campanha adotada por este. Visto que o candidato oficial tem livre acesso aos templos, necessitando apenas que sua presença seja anunciada pelo pastor presidente

Debates do NER, Porto Alegre, Ano 7, N. 10, P. 27-37, JUl./DeZ. 2006 
da congregação, enquanto que o candidato não-oficial, não possui a mesma liberdade, carecendo ser convidado, pressupondo uma relação de afinidade com a liderança da igreja.

A partir das diferentes percepções em relação ao pleito, pode-se constatar que na visão do Pastor Reinaldo, o processo ocorreu de forma harmônica, sem conflitos. Isso porque para o Pastor Reinaldo, a escolha ocorreu dentro das regras do processo democrático, em que ele foi escolhido para ser o representante da Igreja no âmbito federal, enquanto o Pastor Uberani Barbosa foi escolhido para estadual, ganhando de Nilo Santos na prévia interna realizada na IEQ - o Pleito.

Entretanto, conforme disse o candidato Nilo Santos "o processo foi totalmente irregular". Vis to que ocorreu de forma desigual e in justa, pelo fato do Pastor Rein aldo ter sido o presidente da IEQ no estado, em exercício na época, e ter decidido fazer uma "dobradinha" com o Pastor Uberani. Nilo acrescenta que apesar de ter-se indicado à candidatura, seu nome não apareceu na circular enviada aos pastores, dificultando sua divulgação interna. Comentou ainda que somente no dia da prévia conseguiu apresentar-se como candidato, obtendo alguns votos e lamentou que muitos pastores não compareceram à prévia por pensarem que a escolha já estava decidida.

\section{ANALISANDO A FORMAÇÃO DISCURSIVA DOS CANDIDATOS}

$\mathrm{Na}$ análise a seguir iremos tratar tanto da candidatura oficial ao cargo de Deputado Federal, do Pastor Reinaldo Santos, quanto do candidato não-oficial, Nilo Santos, para isto faremos uso de dados coletados junto aos candidatos, sendo estes compostos de: entrevistas, discursos midiáticos, biografias, etc. Ao mesmo tempo, buscaremos explorar as diferentes estratégias, projetos e expectativas de campanha, além de apresentarmos suas respectivas percepçõos sobre o envolvimento entre a religião e a política.

\section{A candidatura oficial do Pastor Reinaldo Santos}

Reinaldo Santos e Silva, 57 anos, nasceu em Miracema, Rio de Janeiro, ingressou na política em 1989 quando foi eleito vereador em Santo Ângelo. Atualmente reside e é Pastor da IEQ em Santo Ângelo/RS, superintendente regional da Igreja no estado e vicepresidente da Frente Parlamentar Evangélica, exercendo o seu primeiro mandato como Deputado Federal pelo PTB, na tentativa de reeleição.

Em seu discurso eleitoral ${ }^{6}$ fez alusão ao seu cargo de pastor, defendendo a luta pelo fortalecimento dos valores éticos, morais e familiares, da inclusão social dos portadores de

${ }^{6}$ É importante salientar a presença e a contribuição, nos pontos questionados na entrevista, de sua assessora e chefe de gabinete Damares Alves.

Debates do NER, Porto Alegre, ANo 7, N. 10, P. 27-37, jul./Dez. 2006 
necessidades especiais, assistência aos demissionários e aos indígenas. Entre suas motivações para inserção na política destaca o interesse em garantir a liberdade religiosa e os benefícios do Estado nas atividades em que a Igreja não pode suprir. Pois observou que as pessoas que freqüentam as igrejas têm uma carência de proteção social, ressaltando a visão assistencialista do Estado.

$\mathrm{Na}$ propaganda eleitoral televisiva, o candidato Reinaldo Santos defende os valores religiosos $^{7}$ reforçando a sua intenção de ser reeleito, direcionando seu discurso ao povo evangélico, como podemos observar a seguir:

"Povo gaúcho, quero ser novamente seu Deputado Federal, o deputado da família. Defendo a valorização e o fortalecimento da base da sociedade. Na câmara federal, sou vice-líder do PTB. Represento os cristãos evangélicos do Rio Grande. O PTB de Zambiasi aposta num futuro melhor e por isso continua com Rigotto, porque só ele pode fazer mais pela nossa gente. Por isso eu peço seu apoio, vote Pastor Reinaldo 1420”.

Ao questionarmos sua preferência pelo PTB, este respondeu que possui uma afinidade com o Senador Sérgio Zambiasi, orgulhando-se da história do partido no Rio Grande do Sul. Destacou também a abertura do partido à participação dos evangélicos, além do fato de o PTB ser, por si só, um partido que já possui um bom coeficiente eleitoral que garante a eleição de muitos candidatos ${ }^{8}$, independentemente do uso do artifício religioso para a obtenção de votos.

Quando questionado sobre os apoios que recebeu em sua campanha, Reinaldo Santos destacou o apoio da própria IEQ, da convenção da Assembléia de Deus Madureira e de outras pequenas denominaçóes religiosas. Conta também com a adesão de instituições como a Apae, a Associação Estadual dos Obesos Mórbidos e o Movimento em Defesa da Vida. Do ponto de vista financeiro, expressa a modéstia de sua campanha como sendo "franciscana" ao dizer que conta com apenas sua chefe de gabinete e "pessoas chaves" em diversas cidades, como pastores voluntários e alguns vereadores.

Sobre sua pretensão de votos nessa eleição disse que, após realizar uma projeção, estimou um mínimo sessenta e cinco mil votos, "mas tem que buscar o voto até quando faltar um minuto para as cinco da tarde no dia primeiro de outubro". Quanto à concorrência eleitoral, expõe que sua principal preocupação é com os políticos de carreira, candidatos do mesmo partido, referindo-se ao candidato Nilo Santos somente quando questionado, definindo-o como:

“(...) um candidato, digamos, rebelde, (risos) ele não está dentro do que a gente chama, den tro do princípio estatutário, esses princípios aí que estão nos estatutos da Igreja.”

\footnotetext{
${ }^{7}$ Referindo-se na entrevista sobre seu posicionamento contra o aborto e a união civil entre homossexuais.

${ }^{8}$ Para maiores detalhes ver texto de Oro e Schoenfelder neste mesmo número.
} 
Continuando com sua análise, refere-se à relação entre religião e política, dizendo que "a política é a arte de administrar", citando passagens bíblicas de homens "usados por Deus" na política, como forma de comprovar a aproximação e a estreita ligação entre as duas. Fato que pode ser observado em sua página na internet ${ }^{9}$, onde aparece em uma foto no seu gabinete com a Bíblia aberta sobre a mesa. Representando que a política não deve ser dissociada da religião.

\section{A CANDidATURA NÃO-OFicial de Nilo SANTOS}

Nilo Santos, natural da cidade de São Francisco de Assis, interior do Rio Grande do Sul, têm 38 anos e ressalta em seu discurso a sua trajetória de vida, expondo que é oriundo de uma família pobre, do interior e que conseguiu prosperar na capital com muito trabalho e honestidade. Nas eleições de 2000 para a disputa de uma vaga na câmara de vereadores de Porto Alegre, Nilo Santos, na época representante oficial da IEQ, recebeu um total de 2.333 votos, não sendo eleito (Oro, 2000). Em 2004, concorreu novamente como candidato oficial da IEQ, disputando o cargo de vereador de Porto Alegre, totalizando 4.482 votos, que o levou ao cargo de segundo suplente de vereador, pelo PTB (Oro, 2004). Após, foi indicado para ser secretário da Assistência Social e Cidadania da prefeitura de Porto Alegre, afastando-se do cargo aproximadamente seis meses após, devido a divergências internas ${ }^{10}$

Quanto à escolha pelo PTB, resgatou a figura de Getúlio Vargas, lembrando que foi "o homem que inventou o salário minimo", as sociando-o com o assistencialismo. Justifica sua decisão devido à preocupação do partido quanto às questóes relativas ao emprego e ao cuidado com os pobres.

Ao ser questionado sobre seus principais projetos e objetivos, disse que, em primeiro lugar, sua intenção é de entrar com honestidade na política, para influenciar as demais pessoas, visto que o país não precisa de um número maior de leis, enfatizando assim, o problema da corrupção existente na política atual. Dentre suas principais metas, objetiva a abertura de $50 \%$ das vagas da universidade pública para alunos oriundos de escolas públicas; a redução do desemprego e o incentivo às pequenas e médias empresas que contratarem jovens para o primeiro emprego e adultos com idade superior a quarenta anos.

No que se refere ao seu discurso político, não dissocia vida secular de vida religiosa, enfatizando que há uma relação intrínseca entre religião e política. Seu pronunciamento no horário político televisivo foi o mesmo ao longo de toda a campanha:

\footnotetext{
${ }^{9}$ Ver: http://www.pastorreinaldo.com.br

${ }^{10} \mathrm{O}$ candidato explica que estas divergências ocorreram devido às inúmeras irregularidades que observou em alguns abrigos para meninos de rua da cidade. Fato que o levou a elaborar um plano, onde tentou vincular uma entidade evangélica no trabalho de recuperação de crianças, o que gerou conflitos com o trabalho das demais entidades.
} 
"Muitos me perguntam, qual é o meu projeto mais importante como Deputado Federal. Respondo: quero trabalhar com simplicidade e honestidade pois é isso que o Brasil precisa hoje. Nilo Santos 1404. Rigotto gov ernador e Simon senador".

Como podemos ver, a partir deste excerto de discurso, percebemos que o candidato não explicita seu vínculo religioso nem o cargo de Pastor, ressaltando apenas suas qualidades. Embora o faz de outras formas, tais como a forte influência de sua campanha publicitária através dos recursos da mídia como o orkut, onde possui dois perfis, um com 390 e outro com 996 membros, e se apresenta como alguém:

“(...) CHAMADO PARA FAZER A DIFERENÇA, INFLUENCIAR, DECIDIR E BUSCAR FAZER SE CUMPRIR A PALAVRA DE QUE SOMOS CABEÇA E NÃO CAUDA. Um cara legal. Que tem a conviç̧ão de que sem Deus nada podemos fazer, mas é extremamente importante o nosso passo, a nossa decisão fará os nossos sonhos se tornarem realidade em Deus. Sou um político que entrei neste meio para procurar fazer a diferença, para influenciar e não ser mais um influenciado a se preocupar com os seus projetos pessoais e não cuidar das pessoas como deve ser. Gosto de barulho, de muita gente em minha volta, não curto lugar escuro, solitário, triste, fui criado para celebrar, andando sempre para frente, não desanimando pelas coisas que não deram certo, mas sabendo que Deus sempre tem algo melhor para mim e para todas as pessoas que o adoram como um Deus vivo."

No perfil do candidato observamos sua visão sobre o posicionamento que a Igreja deve assumir na sociedade. Pois, quando expressa o ser "cabeça e não cauda", podemos compreender como uma forma de não aceitar passivamente as adversidades sociais, mas sim, ter uma participação ativa no processo. Nota-se também a questão da linguagem, usada especificamente para o público evangélico. Também dispõe de ferramentas como o programa de mensagens microsoft messenger ( $\mathrm{msn}$ ), uma banda musical formada com os membros de sua igreja, participação ativa em encontros e eventos que visam elevar o personagem político, bem como, em sua participação nos cultos, pregações e visitas que realiza às IEQ's do estado e à algumas outras denominações, como a AD.

Isso nos mostra que além de contar com os votos do segmento religioso, procura também obter votos do "povo laico ${ }^{11}$ " visto que ressalta como principal projeto de candidatura, seu comportamento ético, e seu compromisso com a justiça e com a causa dos marginalizados. Tal postura procura deixar explícito que sua inserção no campo político não se furta de sua obrigação ética com o bem comum, independente de crença ou religião.

Referindo-se às pessoas e instituições mobilizadas em sua campanha, citou a ajuda de dois advogados e um engenheiro elétrico (que trabalha com a questão da regularização dos

\footnotetext{
${ }^{11}$ Não no sentido de serem sem religião, mas no de não colocarem em evidência seus pertencimentos e crenças religiosas (Oro, 2004, p.15).
} 
"gatos" nas vilas de Porto Alegre). Sen do que a maior assessoria que recebe vem do povo, da família, de amigos da Igreja e, principalmente, dos jovens. Citou também o apoio recebido em algumas Igrejas $\mathrm{AD}$ e de outras denominaçôes menores, como Jesus é Poder, de Guaíba.

Quando questionado sobre sua pretensão de votos, em entrevista realizada um mês antes das eleiçôes, este expressou ser "um homem de vinte mil votos" e acrescentou: "tenho um mês para multiplicar essa quantidade."

Assim, depois de identificar sua expectativa em relação à eleição, questionou-se a questão da concorrência com os outros candidatos, sendo que Nilo Santos pontuou explicitamente sua ocorrência dentro da IEQ, com o Pastor Reinaldo Santos. Enfatizando a não concordância com suas idéias, projetos e votaçóes na Câmara de Deputados.

Outrossim, observa-se que referente à relação entre religião e política, Nilo Santos expõe que "a política foi estabelecida por Deus, o problema é que a Igreja se distanciou muito da politica". E, para isto, faz referência às citações bíblicas explicando suas relaçóes com a política, pois para Nilo:

“(...) a política está no coração de Deus, a política está em tudo. Quem estabeleceu a autoridade no mundo foi Deus. Tanto que a Bíblia diz que devemos orar pelos nossos governantes e abençoa-los."

De uma maneira geral, Nilo enfatiza o envolvimento entre os dois campos, reafirmando a necessidade de que os princípios morais religiosos, como o "bem e a família", sejam inseridos no campo político. Portanto, podemos observar o resgate dos princípios e valores cristãos na política, visto esta estar carente destes, concluindo que as "duas devem caminhar juntas".

No que se refere à formação discursiva dos dois candidatos temos que ambos fazem referência ao resgate dos valores éticos na política e vêem a inserção de candidatos religiosos no campo político como uma forma de moralizá-lo, diminuindo, com isto, a corrupção. Em relação aos vínculos destes dois candidatos com o campo religioso temos que Reinaldo Santos é o que mais se utiliza de sua imagem construída como Pastor entre os evangélicos da IEQ, com vistas à conquista de votos. No entanto, Nilo Santos, em seu discurso, se coloca como bastante distanciado do campo religioso, mas, alguns elementos transparecem e nos permitem perceber a artificialidade desta separação estabelecida. E por fim, temos que ambos, vêem tanto o campo político quanto o religioso como relativamente próximos e que, ao adentrarem na política, estão a serviço de Deus.

\section{ANALISANDO OS RESULTADOS DAS ELEIÇŌES}

A partir da análise da formação discursiva do Pastor Reinaldo Santos e do candidato Nilo Santos, ao cargo de Deputado Federal, podemos tecer algumas consideraçóes no que tange à percepção destes em relação ao processo eleitoral, ao pleito realizado dentro da 
IEQ e ao apoio recebido dentro na Igreja. Sendo que dentre elas fazemos, especial referência, à análise feita pelos próprios candidatos após as eleiçōes.

Deste modo, findo o processo eleitoral, os candidatos foram procurados novamente e indagados sobre o resultado das eleições. Sendo que, aquém das expectativas dos dois candidatos, o resultado eleitoral não ocorreu conforme o esperado. Nilo Santos obteve 5.155 votos, representando aproximadamente $25 \%$ de sua expectativa total. Enquanto que o Pastor Reinaldo Santos atingiu uma soma de 33.930 votos, menos de 55\% do total esperado.

Ao ser entrevistado, o candidato Pastor Reinaldo Santos, expressou sua surpresa com as eleições, tanto para presidente quanto para o governo do estado, ressaltando que ocorreu um retrocesso no resultado das urnas, mas afirmando que: "as urnas falaram e o que a urna falou tá falado". Quando questionado sobre os fatores que atribui a sua não candidatura, expôs que fez uma "campanha correta, modesta e ética", afir ma ndo ter "que aceitar o resultado das urnas." A pós, acrescentou seu propósito em cont inuar no cargo de Deputado Federal até o dia 31 de janeiro de 2007, participando da eleição em âmbito municipal apenas como espectador, "ajudando com o que se pode fazer".

Já o candidato Nilo Santos afirmou que um dos principais motivos da sua não candidatura deve-se ao fato das pessoas estarem preocupadas, em sua maioria, em votar em uma marca. Disse que esta eleição marcou um "caminho inverso para a melhora do pais", visto que o eleitor não se mostrou preocupado com a questão dos projetos apresentados. Citou as candidaturas da Manuela ${ }^{12}$ e do Mano Changes ${ }^{13}$, aqui no sul, para exemplificar o resultado da publicidade pessoal. Como também a expressiva votação do Clodovil, o qual expôs claramente sua falta de projetos. Mostrou-se decepcionado ao ver candidatos envolvidos em escândalos políticos sendo reeleitos.

Mas, em geral, referiu-se ao processo eleitoral como uma experiência pessoal gratificante, um "caminho longo a ser percorrido", mas que "um dia irá alcançar êxito". Fez uma análise de suas eleiçôes anteriores e ressaltou um aumento percentual de votos de 2000 para 2004, não mencionando o resultado atual. Referiu-se à sua continuidade na política através do cargo de vereador que assumirá por dois anos, em que irá mostrar que "é com trabalho que se muda a cidade, não apenas por um estilo diferente e que é melhor votar em quem trabalha do que votar numa marca".

Diante dos resultados apresentados até então, ficou claro frente à inserção da IEQ na política, que seu procedimento democrático não demonstrou uma eficácia, tanto em relação à concorrência entre os candidatos, quanto no resultado das urnas. Pois se observou que, após as eleições, ocorreu uma divisão dos votos da igreja, visto que, esta possui um número suficiente de membros para eleger, no mínimo, um candidato a deputado federal.

${ }^{12}$ Jornalista, 25 anos, natural de Porto Alegre, atual vereadora da capital, eleita Deputada Federal mais votada no Rio Grande do Sul, com 271.939 votos.

${ }^{13}$ Músico e empresário, 30 anos, é vocalista da banda gaúcha Comunidade Nin-jitsu. Nunca exerceu cargo público, foi a primeira vez que disputou uma eleição, elegendo-se Deputado Estadual, com 42.671 votos.

Debates do NER, Porto Alegre, Ano 7, N. 10, P. 27-37, Jul./Dez. 2006 


\section{REFERÊNCIAS}

CAMPOS, Leonildo Silveira. De políticos de cristo - uma análise do comportamento político de protestantes históricos e pentecostais no Brasil. In: BURITY, Joanildo A.; MACHADO, Maria das Dores C. (Orgs.). Os votos de Deus: evangélicos, política e eleiçôes no Brasil. Recife:FJN, 2006.

ORO, Ari Pedro. Religiāo e política nas eleiçôes 2000 em Porto Alegre (RS). Debates do NER, Porto Alegre, PPGAS/UFRGS, n.3, pp 9-70, set. 2001.

Igreja Universal: um poder político. In: CORTEN, André; DOZON, Jean-Pierre; ORO, Ari Pedro (Orgs.). Igreja Universal do Reino de Deus: os novos conquistadores da fé. São Paulo: Paulinas, 2003.

. Religião e política nas eleiçôes 2000 em Porto Alegre (RS). Debates do NER, Porto Alegre, PPGAS/UFRGS, n.3, pp 9-70, set. 2001.

A Igreja Universal e a política. In: BURITY, Joanildo A.; MACHADO, Maria das Dores C. (Orgs.). Os votos de Deus: evangélicos, política e eleiçôes no Brasil. Recife:FJN, 2006.

MARIANO, Ricardo. Análise sociológica do crescimento pentecostalno Brasil. Tese (Doutorado em Sociologia). Universidade de São Paulo, São Paulo, 2001.

PEDDE, Valdir. “Cabeça, Sim; Cauda, Não!”: Um estudo antropológico sobre os evangélicos na Assembléia Legislativa do Estado do Rio Grande do Sul. Tese (Doutorado em Antropologia Social). Universidade Federal do Rio Grande do Sul, Porto Alegre, 2005. 
